\begin{abstract}
Iranica
Abstracta Iranica Revue bibliographique pour le domaine irano-aryen

Volume 34-35-36 | 2017

Comptes rendus des publications de 2011-2013
\end{abstract}

\title{
Milad Milani. Sufism in the Secret History of Persia
}

\section{Mathieu Terrier}

\section{OpenEdition}

\section{Journals}

Édition électronique

URL : http://journals.openedition.org/abstractairanica/42403

DOI : 10.4000/abstractairanica.42403

ISSN : 1961-960X

Éditeur :

CNRS (UMR 7528 Mondes iraniens et indiens), Éditions de l'IFRI

\section{Référence électronique}

Mathieu Terrier, "Milad Milani. Sufism in the Secret History of Persia », Abstracta Iranica [En ligne], Volume 34-35-36 | 2017, document 4, mis en ligne le 30 juillet 2017, consulté le 26 septembre 2020 URL : http://journals.openedition.org/abstractairanica/42403 ; DOI : https://doi.org/10.4000/ abstractairanica.42403

Ce document a été généré automatiquement le 26 septembre 2020.

Tous droits réservés 


\title{
Milad Milani. Sufism in the Secret History of Persia
}

\author{
Mathieu Terrier
}

\section{RÉFÉRENCE}

Milad Milani. Sufism in the Secret History of Persia. Durham, Acumen, 2013, $234+$ xiv p.

1 Tiré d'une thèse de $\mathrm{PhD}$ en science des religions à l'université de Sidney, cet ouvrage développe une thèse assez radicale : le soufisme persan serait un pur produit de la longue histoire religieuse (macro-history) de l'Iran, témoignant d'une « histoire secrète » de la Perse, celle de courants ésotériques refoulés par l'orthodoxie zoroastrienne puis islamique ; plus encore, le soufisme en général serait un phénomène culturel et spirituel iranien. Cette thèse reprend, tout en la nuançant légèrement, l'historiographie en partie mythologique (myth-history) de la branche Munawwar 'Alīšāhī des soufis Ni‘matullāhiyya et de son quṭb Javād NūrbaȞš (1926-2008).

2 La première partie porte sur ce que l'A considère comme les racines persanes du soufisme. Le chap. 1 introduit l'idée d'une "sagesse khosrovanite » (hikmat-i Husravānī) commençant avec Zarathushtra. Le chap. 2 distingue l'enseignement originel « gnostique " de Zarathushtra du zoroastrisme officiel des Sassanides. Le chap. 3 rapproche les thèmes moraux des Gāthās de ceux du soufisme persan, entendant montrer l'influence du mithraïsme sur celui-ci. Le chap. 4 poursuit une analyse comparative du symbolisme mithraïque et de la tradition soufie persane. Le chap. 5 défend un continuum entre l'antique religiosité persane et le soufisme persan, contestant l'idée, défendue par Lloyd Ridgeon (Morals and mysticism in Persian Sufism), d'un amalgame des cultures iranienne et arabe.

3 La seconde partie du livre porte sur la transmission de cet héritage de l'Antiquité tardive à l'époque islamique. Les chaps. 6 et 7 explorent la piste du néo-mazdakisme comme ferment du soufisme persan, de l'ésotérisme kurde et des courants shi'ites gulāt. L'exposé des doctrines des Ahl-e haqq, des 'Alevis, des Yezidis et des gulāt, est marqué 
par le schème de la résurgence et par l'a priori d'une résistance à l'islamisation. Plus objective, une succession de notices sur les rebelles et hérétiques iraniens comme Bābak Hyorramī (m. 223/838), illustre la fusion précoce du néo-mazdakisme et de l'islam hétérodoxe. Le chap. 7 soutient l'influence du mazdakisme sur la doctrine socioreligieuse de l'islam avec l'hypothèse d'une diffusion précoce du mazdakisme en Arabie et d'une participation mazdakite à la conquête musulmane de la Perse. Le chap. 8 révise le rôle de Salmān le Perse auprès du prophète de l'Islam à la lumière des thèses macro-historiques de différents courants hétérodoxes, d'où il ressort que Salmān, identité secrète de l'ange Gabriel, fut possiblement l'auteur ou le co-auteur du Coran. Enfin, le chap. 9 s'emploie à séparer le soufisme persan, voire le soufisme en général, d'une mystique islamique, en discutant les vues de S. H. Nașr et du " cercle de Téhéran » (Corbin, Țabāțabā'î). En conclusion, l'A. va jusqu'à attribuer la survie du soufisme à " la ténacité psychologique et spirituelle de la Perse »(p. 225).

On l'aura compris, ce livre contient autant de pistes stimulantes pour la recherche comparative que de biais conceptuels - un essentialisme qu'on dirait d'un autre âge - et de partis pris idéologiques grevant sa scientificité. Nolens volens, il montre à quel point il est nécessaire et difficile de faire droit aux interactions des cultures arabe et iranienne dans la longue histoire de l'islam et du soufisme.

\section{AUTEURS}

\section{MATHIEU TERRIER}

Paris 